Media Industries $5.2(2018)$

\title{
Netflix and the Reconfiguration of the Australian Television Market
}

\author{
Graeme Turner ${ }^{1}$ \\ UNIVERSITY OF QUEENSLAND \\ Graeme.turner [AT] uq.edu.au
}

\begin{abstract}
Australian television has always been dominated by free-to-air television. Once protected from extranational competition by its geography and by a regulatory structure which controlled the conditions for entry, the dominance of the commercial channels, in particular, has until now been relatively unaffected by the introduction of pay television and local subscription or streaming services. The arrival of Netflix in 2015, however, was a game-changer; as a telecommunications service, it was not subject to media regulations and thus became the first major transnational media company to establish a beachhead in the Australian market. This article examines the direct and related consequences of this for the market and for those charged with regulating that market in the national interest.
\end{abstract}

Keywords: Australia, Television, Netflix, Media Regulation

\section{Introduction}

For more than six decades since the introduction of television in 1956, and largely as a consequence of its geographic isolation, Australia has been able to control commercial access to its television market and manage its development. Australian authorities have done this, to varying degrees over time and with varying degrees of explicitness, in the service of several objectives: the protection of national sovereignty over its institutions allied with a form of cultural nationalism which privileged the production of a national culture, and the protection of the commercial interests of the established local free-to-air (FTA) television industry. In support of the local industry, successive Australian governments have sought to maintain local majority ownership and control while limiting the allocation of spectrum through formal licensing processes that are politically managed. Historically, it has almost 
been impossible for any new enterprises to enter this market without going through formal regulatory gates that are specific to the medium. In support of a national cultural agenda, governments have mandated minimum levels of locally produced scripted content for commercial broadcast television proprietors, with the explicit aim of ensuring they screen sufficient local content to maintain television's contribution to fostering a "sense of Australian identity, character and cultural diversity." ${ }^{2}$

Under these regulatory arrangements, over much of that period, the structure of the Australian television industry and indeed what constituted "television" for Australians had proven comparatively resistant to developments occurring elsewhere: the globalization of the media industries, the decline of the mass media paradigm, and the multiplication of distribution platforms. While, of course, there are important areas where these developments have exerted significant influence in Australia and especially across other sectors of the media, key elements of the television market had remained more or less unchanged: the dominance of television broadcasting, for instance, and television's major share of the national media advertising spend. That situation has now come to an end. As this article goes on to argue, the arrival of Netflix has proven to be a crucial catalyst for a series of shifts which have turned that history on its head. Subscriber-supported television is challenging the advertising-driven model of the broadcasters, and consumers are being drawn to transnational streaming services which offer greater choice and customization but which have no regulatory obligation to address the national audience. At the level of regulation and control, this is the first time a major transnational intervention into the Australian television market has occurred without going through the specific frameworks established to regulate it in the national interest. This, together with its knock-on effects on the broadcasting industry, has radically disrupted the state, and in the long term likely the future structure, of Australian television.

To be sure, there are many other factors in play here-digital's growing share of the advertising market threatens the business models for all commercial mass media, and the high uptake of mobile devices, accessing YouTube and other video aggregators, as well as social media in general, has played its part in changing the consumption habits of younger audiences, in particular. However, the challenge posed by the introduction of Netflix, and by streaming services in general, is also quite specific: It changes what Australians now see as television ${ }^{3}$ and transnationalizes the makeup of the market. Furthermore, as I go on to suggest in the second half of this article, the seriousness of this challenge for the Australian television broadcasting industry is implicated in a further shift toward its transnationalization: the purchase of one of the three Australian commercial television networks by the American network, CBS. Rather than being regarded as a challenge to the integrity of an Australian television institution, this was widely, although admittedly not universally, welcomed as a means of ensuring its continued viability.

\section{The Netflix Effect}

The Australian television market has always been, and even now remains, dominated by FTA television. It has three commercial networks which are branded with their own identities but which nonetheless compete for their viewers from the same mass market, except for a period 
from the mid-1990s to the mid-2000s when the TEN network broke ranks to target a youth demographic. ${ }^{4}$ There are two publicly funded FTA networks: a national public broadcaster modeled on the BBC (the ABC) which is commercial-free, and the national multicultural network (SBS) which takes a slightly restricted range of advertising. Today, 86 percent of television viewing in Australia is via FTA TV, ${ }^{5}$ with news, reality programming, and sport the top rating genres. By international standards, this is a high percentage for broadcast viewing; however, things are changing. Over 2017, the FTA audience was down by 5 percent (10 percent if you take out the baby-boomers), television's share of the advertising pie shrunk by 4 percent, ${ }^{6}$ and a clear age-related division has developed in the mass market audience demographics (traditional TV is fast losing the 18-39s). ${ }^{7}$ It has been claimed that as much as one in seven Australian consumers will watch no FTA TV at all on a normal weekday (that leaps to one in five for the under-thirty-five-year-olds ${ }^{8}$ ) and Australians watched more than eighty minutes less television per week in 2017 than they did in 2015. The loosening of the FTA networks' stranglehold on television viewing in Australia has generated something close to panic among the FTA broadcasters, who have been lobbying government for support with increased urgency over the past two years. Government has responded by developing a raft of "reform" measures, aimed at improving the broadcasters' commercial prospects. The "game-changer" which has precipitated this situation, according to the networks as well as other stakeholders-and the Television: $2025^{9}$ interviews with industry representatives demonstrate this very clearly-has been the competition created by the arrival of Netflix.

The Australian FTA networks have dealt with competition before; the introduction of pay TV in 1995 cut into the FTA market. Initially, there were several pay-TV providers in competition, but now there is only one nation-wide provider, Foxtel, which is part-owned by NewsCorp. Foxtel has a penetration rate of around 27 percent nationally, and this has not shifted much in the past five years, as subscriber churn has wiped out any significant gains. The static levels of subscription are largely the result of Foxtel's insistence on maintaining its relatively high pricing (roughly four times the price of a Netflix subscription and with premium sport channels in the highest price band) and their practice of bundling packages of channels which include many options consumers do not actually want. The broadcasters have also adopted initiatives which have strengthened their capacity to compete with Foxtel. The development of an Australian version of the United Kingdom's Freeview platform has enabled the FTAs to compete with the multichannel offerings on pay, by offering a total of (currently) around twenty digital channels on FTA, including some niche channels of the kind customarily offered to pay subscribers (lifestyle, cooking, and real estate, for instance). Gradually surrendering the development of locally produced quality drama to Foxtel and more recently to the local streaming service, Stan, the FTAs have focused their investments on live and local programming such as local news, competitive reality, events, and sport. The multiplication in the number of channels and the concentration on these commercial genres, in addition to the development of catchup or time-shifting services, have led the FTA networks' relatively successful competition with pay TV. The FTA channels and Foxtel do screen advertisements, however, and this remains a significant reason for consumers to watch their preferred content via the streaming services.

Netflix, as is the case with several of the US-based subscription video on demand (SVOD) providers, had an informal subscription base in Australia for some years before its official Australian launch. It is reputed that something of the order of two hundred thousand 
Australians used virtual private networks (VPNs), BitTorrent, and other methods to access the Netflix catalog and view downloads well before 2015. The high-quality profile of Netflix and HBO drama productions such as House of Cards and Game of Thrones (and these are just two of the most prominent among many other examples of non-FTA international high-end drama production) had helped to create a transnational market that was at least partly constructed outside the conventional broadcasting industry structures. In Australia, such content had become a highly desirable and commercially significant component of the television-viewing habits of the younger market in Australia-eighteen- to thirty-nineyear-olds-although they were only available through illegal downloads or the purchase of box sets of DVDs. Neither House of Cards nor Game of Thrones has ever been screened on FTA in Australia, although both were available through premium packages on Foxtel. Streaming services that might offer affordable (and legal) access to such content were therefore eagerly awaited.

When Netflix was finally introduced to Australia in 2015, it picked up 10 percent of the market within three months ${ }^{10}$ ! Currently, after just a little more than two years, it has a reach of 7.6 million, which amounts to 2,988,000 households, or almost 32 percent of the market ${ }^{11}$; this exceeds the reach of linear pay TV (27 percent). ${ }^{12}$ Most significantly, while there was limited evidence of much change in actual viewing habits in response to the take-up of pay $\mathrm{TV}$, there is clear evidence that Netflix is having such an effect. Linear viewing now is in decline ${ }^{13}$ and that is starting to be reflected in the configuration of platforms used in consumer households: the mix of FTA, SVOD, and pay, as well as the choice of devices in use. ${ }^{14}$ Furthermore, while the demographics for the FTAs skew old (and skew older as time goes by), the demographics for Netflix subscribers skew young-a factor that the FTA networks regard as a sign they face even greater disruption in the future. ${ }^{15}$

As noted earlier, and notwithstanding the tendencies toward deregulation that generated some structural change over the 1980s and early 1990s, Australia has long had a significantly regulated television market. In addition to paying substantial license fees for their use of spectrum, the FTA networks also have public interest obligations to discharge: There are mandated levels of local content (55 percent) and restrictions on categories of content at particular times of the day (children's programming and alcohol advertising, for instance). Network governance includes some self-regulatory codes of practice affecting, for instance, the content and scheduling of advertising. The public broadcasters are required to meet a set of charter obligations to do with cultural diversity and comprehensive service provision. Most importantly, to say that access to this market has been highly restricted would be an understatement. Granting a new license is a rare and major political event; the most recently licensed of the commercial networks, TEN, commenced operation in 1964, and the introduction of pay TV occupied many government inquiries over decades before it finally occurred in 1995. The establishment of the pay-TV providers and their corporate connections to other local and overseas media companies were also overseen by the national regulatory authorities.

What was so distinctive about the introduction of Netflix to the Australian media market was that Netflix was subject to none of this. Of course, transnational media companies have long been major components of the makeup of Australian movie industry, the metropolitan print media, and so on, but Netflix is the first foreign-based or transnational provider to enter the 
Australian television market without going through any of the standard national regulatory gates for the medium. As it was not a broadcaster, and as it was not seeking a license to operate a stand-alone pay-TV service made available via modifications to the telecom infrastructure, it exploited a gap in the regulatory framework for the Australian media and communications infrastructure that the Convergence Review ${ }^{16}$ had warned about and that had gone unheeded. As an SVOD service, Netflix fell under the regulatory regime for telecommunications services, not the media; crucially, these services are not held responsible for the content they carry. Consequently, Netflix was not subject to the requirements on ownership, local content, and so on that constrained the FTA networks-although it is clear that they were to be in direct competition with these networks. ${ }^{17}$

The speed of Netflix's take-up has left the networks flabbergasted as they have watched their viewing base decline and as they lose an increasing proportion of the younger demographic and thus the opportunity to train viewers' behavior for the future. As they have come to accept their incapacity to compete with the production values in high-end drama being produced by the likes of HBO and Netflix, they have expressed deep resentment at the restrictions on their ability to respond commercially, which come from their enclosure within a regulatory regime that does not similarly constrain Netflix-or any other transnational telecommunications service provider such as Amazon who is in the market already, or Hulu, who might enter the market in the future. In such a context, it is not surprising that, in 2017, the commercial FTA networks sought government intervention as a means of countering the disruption to their businesses that Netflix represents.

In commercial terms, the extent of that disruption is serious. The Nine network, for many years the market leader who once referred to its business as a "license to print money," massively wrote down its value while reporting a loss of US\$237 million for the six months to December 2016, with FTA earnings for the network declining over that period by 9 percent. ${ }^{18}$ The composition of the daily linear schedule is showing the effects: Nine's afternoon programming from 3 to 7 p.m. is almost entirely recycled news, and competition reality shows are wall to wall in prime time. With commercial television aiming for shows that people will watch live, share on social media, and talk about next day, it is clearly locked into what Amanda Meade has called a "battle for the water cooler."19 With less linear or appointment viewing taking place, and word of mouth via social media (rather than traditional methods of advertising or promotion) looming as a substantial influence on viewer behavior, that battle is getting harder all the time.

Some of this is not new, of course. The FTA networks have long chafed at the restrictions placed upon their behavior by their public interest obligations and so they have happily embraced the opportunity for winding back these obligations that this battle provides. And it is not just Netflix that is taking the blame here; there are other transnational influences at play as well. The Australian Consumer and Competition Commission has undertaken a review of the disruption caused to the advertising market by Facebook and Google, with particular attention to the impact on journalism. There are claims that digital advertising as a whole now constitutes 54 percent of the total national advertising market. ${ }^{20}$ Over the first half of 2017, consequently, the commercial broadcasters lobbied government vigorously for the abolition of local content quotas and their license fees-indeed the abolition of any regulatory requirement that would differentiate them from Netflix or from pay TV. ${ }^{21}$ Although there 
has certainly been a deregulatory mood for some years in Australia, the government was never likely to abolish all protections of the public interest for this industry. Nevertheless, the broadcasters have won some concessions. The media "reforms" recently legislated significantly reduce restrictions on ownership and reach, enabling greater economies of scale and the establishment of fully national networks. License fees have been replaced by a much lower "spectrum fee," and a AU\$60 million support fund will be established for some small and regional media outlets affected by the media concentration likely to result. There is also to be a review of the "anti-siphoning" 22 list to help sports broadcasters and Foxtel.

These are all reactive responses to the current situation, however, and do not address the substantive issues facing a regulatory regime that is increasingly unfit for the purpose of managing a convergent media and telecommunications environment. The underlying problem for the regulators remains: how to find a way of deciding whether, or how, the public interest purpose of such things as local content conditions should apply to distributive media and communications platforms or "portals"23 other than television. Furthermore, the production industry has argued that it is manifestly unfair if only the broadcasters are required to meet legislated levels of investment in the local industry when they are not the only ones seeking to profit from their activities in this market. And finally, from the public's point of view, there is little benefit in abandoning the cultural nationalist principles which have historically undergirded the policy settings for the structure of the local television industry simply because the operating environment has changed. None of these issues are resolved by the current raft of media reforms.

There is also the question of what all of this does to what we might now think of as the Australian television market, given that there are ways in which Netflix could argue that it is not television. Certainly, it does not constitute a direct threat to the broadcasting industry in the way that pay TV had done. It does not compete for the advertising dollar, it is true, but it does compete for the audience numbers that determine the rates at which advertising is sold. However these questions are resolved, the impact of Netflix is not just that of a "foreign" intervention; its implications are more deeply structural. It connects Australian television to the transnational logics of digital convergence and industry consolidation that have been playing out globally in both the technology and the media industries-but which have taken some time to much affect the shape of the television industry in Australia. These logics have also played a significant part in creating the conditions for the second part of this narrative.

\section{CBS and TEN: The Acceptable Face of Foreign-Owned Media}

For many years, Australia had restricted foreign investment into the Australian television industry with caps on levels of investment and the capacity to control. These had always been regarded as a little rubbery and often challenged; the fact that Rupert Murdoch, for instance, as a former Australian citizen, was (and still is) treated differently than any other foreign investor exposed the inconsistencies in play. Over the years, there had been a number of calls to allow higher levels of foreign investment into the Australian broadcast 
television industry in the past; the Nine network, for instance, attempted a deal with the American giant CBS in 1990, but had their initiative blocked. Eventually, in 2007, those regulations specific to television were scrapped, although the principles implicit in them-the general principles underlying regulation in the national interest noted at the beginning of this article-still retained their force; they were, however, to be managed by the Foreign Investment Review Board rather than by a media industry regulator. Even after the rules were relaxed, however, there have been situations where existing foreign investors have gradually increased their stakes to test the environment, only to meet with resistance. In a highly contentious deal, Canadian media company CanWest received approval to take a 56 percent stake in the troubled TEN network in 2007. Despite a number of political restrictions on the structure and operation of the company aimed at limiting their actual influence and control, CanWest was able to gradually increase their stake in TEN over the next two years. Eventually, they hit a regulatory wall: When CanWest's interest reached 76 percent, regulators demanded that they divest back down to a level of 15 percent. This eventually became a diplomatic issue, with the Australian and Canadian governments trading blows, but in the end, when CanWest finally sold its interests in TEN in 2009, they stood at around 50 percent.

As is the case with other elements of the Australian regulatory framework, the regulatory oversight of the foreign ownership of broadcasting companies has three core considerations: the need to protect the commercial interests and viability of the local broadcasting industry, the need to support the local production industry, and the more abstract but nonetheless important concern for protecting the public interest through, among other things, maintaining sovereignty over Australia's media institutions. Even without the earlier cap on investment, these principles are still invoked as worth acknowledging and implementing. It is highly significant, then, that the American broadcaster CBS's 2017 purchase of Network TEN-which at best satisfied only one of these objectives-did not generate the alarm that might once have occurred.

Network TEN has been under commercial pressure for most of the past decade and has restructured several times over this period. TEN's woes had increased as the demographic it had so successfully served during the 1990s and early 2000s (what was at times called "extreme youth," the fourteen- to thirty-nine-year range) was precisely the demographic which responded so enthusiastically to the multichannel environment and to the emerging alternatives to mainstream traditional media-both in terms of the content sought and in terms of the platforms and devices used to consume that content. ${ }^{24}$ This was exactly the section of the market that has increasingly chosen not to watch FTA television; to be sure, they may still watch multiple episodes of The Big Bang Theory but they do not do it via linear TV. TEN was forced into a change of strategy, but its attempt to compete with the two other networks for a viable share of the mass market failed, generating considerable public and industry debate about its likely survival. ${ }^{25}$ In April 2017, TEN reported a half year loss of US\$247 million, triggering a major write-down of the network's value and eventually the appointment of receivers. The viability of the network was further threatened when key financial backers-Lachlan Murdoch, James Packer, and Bruce Gordon-withdrew their support, possibly in the hope of precipitating a fire sale that would hand control over to a consortium led by Gordon and Murdoch. 
The fire sale never eventuated, however. For a variety of complicated reasons, the withdrawal of their financial backing opened the way for bidders other than the Gordon-Murdoch consortium. While this may have been foreseen, it was perhaps not taken as a serious problem because there was no likely alternative bidder within Australia. What had not been foreseen was the successful intervention of a foreign bidder. In August, the CBS purchase of TEN was announced. Notwithstanding concerns about the level of foreign ownership, the fact that TEN was in receivership meant that this bid could be seen as preserving current levels of competition and thus was in the national interest. Furthermore, CBS's status morphed from that of a major creditor of the failed network-it had long-term content deals with TEN-to that of a white knight which would effectively guarantee the network could commence the next phase of its operation debt-free. To cap it off, CBS's history as a television network with a longstanding commitment to news and current affairs could be regarded as enhancing the public benefit flowing from TEN's survival.

The purchase did have to seek the approval of the Foreign Investment Review Board, but despite the appeals from the gazumped Gordon-Murdoch consortium and the long regulatory history of resisting high levels of foreign ownership of Australian television, it was widely applauded as a positive development and met with no significant opposition from either side of politics. One can speculate about the reasons for this, but it may have to do with concerns about the role of NewsCorp and the Murdoch family in the concentration of media ownership in Australia. Apart from the continuing concern at regulators long choosing to turn a blind eye to Rupert Murdoch's status as a former citizen who is now a foreigner, many would also argue that Murdoch's dominance of the Australian print media has been disastrous for public debate; the strident use of his media outlets for political influence has spooked both sides of politics over the years. If it has been a case of "anyone but Murdoch," the fact that CBS is arguably the most respected of the American broadcast networks came as a bonus and emphasized the comparison. So, whereas on another occasion a takeover bid from an American multinational broadcaster might have generated concern about the loss of sovereignty over Australia's media, the CBS bid was generally seen as salvation. The result of the bid is that TEN now looks viable and likely to be a serious competitor in the broadcasting market into the future. Ironically, this is precisely because of TEN's enclosure within a major multinational media corporation.

The confluence of events outlined here-the arrival of Netflix, the transformations of the media markets resultant upon the rise of multichannel, multiplatform, and transnational choices; and the knock-on effects of these transformations upon the least competitive of the three commercial television broadcasters-amounts, I would argue, to a radical transnationalization of the Australian media.

\section{Conclusion}

The above account has focused on the way things look from the point of view of the broadcasting networks, and to a lesser extent the regulators. There are other points of view, of course, which though less powerfully represented do complicate predictions of how the current phase of disruption will ultimately play out. The pay-TV industry recognized the 
threat from SVOD earlier than the commercial FTA networks; as part of their response, Foxtel increased their investment in high-quality local production. At the most recent industry awards, the Logies, Foxtel emerged as the leading player in quality television drama production. This is generating improved ratings for them, and it has contributed to their competitive strategy: a strong presence in news, sport, and high-end local drama. ${ }^{26}$ Foxtel has a deal with HBO, which means that every new HBO series will be available first on Foxtel: They will be the first to screen new series of Game of Thrones, Girls, Divorce, Westworld, Veep, and a number of others. ${ }^{27}$ For the moment, then, particularly as they begin to move further away from linear models of viewing with Foxtel Now, Foxtel seems to have a reasonable midterm strategy for survival in which investment in local production is now an important element. While Foxtel claim that they are less exposed to the threat from Netflix than the FTAs, it remains to be seen whether that is the case. Taking the local production route is expensive and does carry a risk; although it has paid dividends in the ratings and in critical opinion, it has not so far exercised an influence on the volume of subscriptions.

The local content producers have taken a different position to the FTA networks; they are concerned with the survival of a local production industry. Netflix has talked of investing in local production, ${ }^{28}$ but there has so far only been one production commissioned and little sign of activity beyond that at the time of writing. The screen production industries want government to offer more in the way of incentives for local production; there is a long and positive history of such incentives generating substantial economic and cultural dividends in Australia, so it would not be entirely surprising if politicians and other policy-makers chose to support them. The CEO of Screen Producers of Australia, Matthew Deaner, has suggested transnational companies such as Netflix should be required to pay a price for their opportunity to operate in the local market:

"These are big, disruptive, successful businesses that have had time to expand in this market without making any significant investment in local production. It's time they step up to the plate and contribute to new Australian film and television production." ${ }^{29}$

The production industry is suggesting that local content quotas be extended (rather than abolished as the FTA broadcasters had proposed) and that there be some mechanism to require mandated levels of investment in the production of new content as well. The failure to place SVOD services like Netflix "under the same mandates as their broadcast counterparts," they say, constitutes "a wasted opportunity that threatens to undermine the longterm investment in the local screen industry and lags behind a wave of global momentum toward incentivizing and obligating VOS investment in domestic sectors. " ${ }^{30}$ At present, without such incentives, the level of local investment required of transnational "disrupters" falls well behind, for instance, levels currently being considered by the European Commission: requiring SVOD services to provide at least 20 percent of European content in their libraries, as well as demanding Netflix tweak their algorithms to ensure European content is as easy to discover as US titles. ${ }^{31}$

To conclude, then, I am arguing that the arrival of Netflix represents a key point in Australian television's transition from a national, largely broadcasting, market to a transnational multiplatform market. This market is now a site of both technological convergence and considerable 
consumer divergence. There is strong evidence that the rapid take-up of Netflix is changing the patterns of consumption within households and the shape of the local media economy on all levels-production, distribution, and consumption. At the level of content, it has significantly accelerated the transnationalization of the content available to Australians and holds implications for how a local production industry might respond to the threats and opportunities this development carries with it-to do with the place of local content on streaming services and issues of discoverability for that content. In regard to a regulatory system that has been fundamentally national(ist)-in process and in principle-Netflix has revealed the implicitly anachronistic character of its assumptions about the nature of the industry it is charged with regulating while also implicitly challenging the "nationing" 32 principles upon which it has been based.

The CBS purchase of TEN further reinforces that view. Not only does it represent a significant acceleration of Australian television's integration with the consolidating dynamics of transnational media industries, it also probably marks the end of a policy stance which preferred the local broadcasting networks to be under majority control of Australian owners. While in the broader context of industry changes around the world-such as the decline of broadcasting, the rise of the digital, the fragmentation of media audiences, and the globalizing tendencies right across the media industries - the purchase may seem unsurprising, it constitutes a decisive break with the history of national policy in this area and thus plays a prominent role in the complex of transnational interventions that are influencing the reconfiguration of the television industry in Australia.

${ }^{1}$ Graeme Turner is Emeritus Professor of Cultural Studies in the Institute for Advanced Studies in the Humanities at the University of Queensland. His most recent book is Re-inventing the Media (Routledge, 2016).

${ }^{2}$ Lauren Carroll Harris, "When Will Netflix Start Investing in Australian Content?," Australian Centre for the Moving Image, October 7, 2016, acmi.net.au/acmichannel/2016/when-will-netflix-start-investing-in-australian-content/.

${ }^{3}$ In another research project in which I have been involved, Australian Cultural Fields, led by Tony Bennett and funded by the Australian Research Council, the research team conducted forty-five interviews with consumers about their choices of television and their modes of access. The full account of this material is still being prepared for publication, but the vast majority of respondents under-thirty-five consumed "television" through Netflix and were "over" free-to-air broadcast TV.

${ }^{4}$ The shift from analog to digital initially allowed each network to add three new digital channels, and this, together with the increasing use of, at first, DVD box sets and then later on downloads via BitTorrent and offshore virtual private networks (VPNs) to access highly reputed international content, as well as the rise of social media entertainment such as that available via YouTube, ate into that youth market. This demographic is now the heartland of the new media audience, not a viable focus for mass market broadcasters.

${ }^{5}$ Darren Davidson, "Seven, Ten, Nine Red Ink the Signal for Television Reform," The Australian, February 24, 2017, www.theaustralian.com.au/business/media/ opinion/seven-ten-nine-red-ink-the-signal-for-television-reform/news-story/ cb4e56cede79b262de7d578dc45da436. 
${ }^{6}$ Neil Chenoweth, "For Seven, Ten, and Nine: It's the End of the Party," Australian Financial Review, February 17, 2017, http://www.afr.com/business/media-andmarketing/tv/for-seven-ten-and-nine-its-the-end-of-the-party-20170216guemu5.

${ }^{7}$ Davidson, "Seven, Ten, Nine Red Ink."

${ }^{8}$ Adam Turner, "Is Netflix Hurting Aussie Broadcasters? Depends Who You Ask," The Age, March 11, 2016, https://www.theage.com.au/technology/is-netflix-hurtingaussie-broadcasters-depends-who-you-ask-20160311-gngcvq.html (accessed June 30, 2016).

${ }^{9}$ Jock Given, Gerard Goggin, Michael Brealey, and Cathy Gray, Television: 2025: 20 Questions, 24 Viewpoints (Swinburne: Swinburne University of Technology, 2015).

${ }^{10}$ Simon Thomsen, "Netflix Just Cracked 10\% of the Australian Market," Business Insider Australia, October 15, 2015, https://www.businessinsider.com.au/netflixjust-cracked-10-of-the-australian-market-2015-10.

11 Roy Morgan Research, "Netflix Hits New High in Australia-7.6 Million," September 28, 2017, www.roymorgan.com/findings/7343-netflix-subscriptionsjune-2017-201709270713.

12 Roy Morgan Research, "More Australians Now Have SVOD than Foxtel," Article No. 6957, September 8, 2016, www.roymorgan.com/findings/6957-svod-overtakesfoxtel-pay-tv-in-australia-august-2016-201609081005.

${ }^{13}$ Morgan, "Netflix Hits New High."

14 This is also among the early findings from the Australian Cultural Fields project; over half the interviews had altered their patterns of use in significant ways since the introduction of Netflix; many had stopped watching free-to-air (FTA), some were accessing most of their media content through laptops or iPads, and around a third had subscriptions to Netflix.

${ }^{15}$ Netflix is not the only subscription video on demand (SVOD) provider in the market; the Australian company, Stan, affiliated with one of the FTA networks, and with a greater presence for Australian-produced material in its catalog, has seven hundred thousand subscribers. Another Australian provider, Presto, backed by one of the other commercial FTA networks, has folded, however, and it is clear that there is still much sorting out to be done before the makeup of this market will be settled.

${ }^{16}$ Commonwealth of Australia, "Convergence Review: Final Report" (Canberra: Department of Broadband, Communications and the Digital Economy, 2012).

${ }^{17}$ In retrospect, it is surprising that the market gap Netflix exploited had been left vacant by the FTA networks, who had only responded reluctantly and late to the possible threat from SVOD by each setting up their own comparatively small-scale SVOD operations (Stan and Presto) rather than, for instance, joining forces in a consortium that might have aggregated a catalog on a much more competitive scale.

${ }^{18}$ Lucy Battersby, "Nine Reveals Massive Write-Down in Value of Its Television Network, Leading to \$237 Million Loss," Sydney Morning Herald, February 23, 2017, www.smh.com.au/business/media-and-marketing/nine-reveals-massive-writedown-in-value-of-its-television-network-leading-to-237m-loss-20170222-guj7zk. html. 
${ }^{19}$ Amanda Meade, "Australia's TV Channels Plunge into the Battle for the WaterCooler," The Guardian Australia, February 12, 2017, www.theguardian.com/ tv-and-radio/2017/feb/12/australias-tv-channels-plunge-in-to-the-battle-forthe-water-cooler.

${ }^{20}$ Lindsay Bennett, "Digital ad Spend to Overtake TV in 2017, Studies Find," Adnews, March 28, 2017, www.adnews.com.au/news/digital-ad-spend-to-overtake-tv-in2017-studies-find.

${ }^{21}$ Davidson, "Seven, Ten, Nine Red Ink."

${ }^{22}$ This is a government list of events, primarily sporting events, which are considered to be of sufficient national importance that they cannot be acquired as exclusive content by pay TV; the aim is to ensure that these events are universally available to FTA viewers.

${ }^{23}$ Amanda Lotz, Portals: A Treatise on Internet Distributed Television (Ann Arbor, MI: Maize, 2017).

${ }^{24}$ Michael Idato, "Clinging to the Remnants of Youth," Sydney Morning Herald, September 17, 2012, http://www.smh.com.au/entertainment/tv-and-radio/ clinging-to-the-remnants-of-youth-20120913-25vmk.html.

${ }^{25}$ Peter Ryan, “Ten Network Casts 'Significant Doubt' Over Its Viability," The World Today, ABC News, April 27, 2017, http://www.abc.net.au/news/2017-04-27/tennetwork-struggles-to-survive-after-another-big-loss /8475774.

${ }^{26}$ The latter is a major shift; previously and at various points in the Australian industry's history, the ABC, SBS, and two of the commercial networks were the leaders in local drama production.

${ }^{27}$ At the same time, seven out of Foxtel's top ten shows were Australian productions (Davidson, 2017).

${ }^{28}$ Harris, "When Will Netflix Start Investing."

${ }^{29}$ Marc C-Scott, "Is a Quota the Key to Getting Netflix and co. to Spend More on Australian Content?" The Conversation, June 6, 2016, https://theconversation.com/is-a-quota-the-key-to-getting-netflix-and-co-to-spend-more-onAustralian-content-60308.

${ }^{30}$ Harris, "When Will Netflix Start Investing."

${ }^{31}$ Ibid.

${ }^{32}$ An account of the decline of "nationing"-that is, the development of national culture through the explicit use of cultural policy-in television policy is published in Graeme Turner, "Television: Commercialization, Transnationalism, the Decline of "Nationing' and the Status of the Media Field," in Making Culture: Commercialisation, Transnationalism, and the State of 'Nationing' in Contemporary Australia, ed. David Rowe, Graeme Turner, and Emma Waterton (London: Routledge, 2018), 64-74.

\section{Bibliography}

Battersby, Lucy. "Nine Reveals Massive Write-Down in Value of Its Television Network, Leading to \$237 Million Loss." Sydney Morning Herald, February 23, 2017. www.smh. 
com.au/business /media-and-marketing/nine-reveals-massive-write-down-invalue-of-its-television-network-leading-to-237m-loss-20170222-guj7zk.html.

Bennett, Lindsay. "Digital Spend to Overtake TV in 2017, Studies Find." Adnews, March 28, 2017. www.adnews.com.au/digital-spend-to-overtake-tv-in-2017-studies-find (accessed May 10, 2018).

Chenoweth, Neil. "For Seven, Ten, and Nine: It's the End of the Party." Australian Financial Review, February 17, 2017. http://www.afr.com/business/media-and-marketing/ $\mathrm{tv} /$ for-seven-ten-and-nine-its-the-end-of-the-party-20170216-guemu5.

Commonwealth of Australia. "Convergence Review: Final Report." Canberra: Department of Broadband, Communications and the Digital Economy, 2012.

C-Scott, Marc. "Is a Quota the Key to Getting Netflix and co. to Spend More on Australian Content?" The Conversation, June 6, 2016. https://theconversation.com/isa-quota-the-key-to-getting-netflix-and-co-to-spend-more-on-Australiancontent-60308.

Davidson, Darren. "Seven, Ten, Nine Red Ink the Signal for Television Reform." The Australian, February 24, 2017. www.theaustralian.com.au/business/media/opinion/seventen-nine-red-ink-the-signal-for-television-reform/news-story/cb4e56cede79b262de7d578dc45da436.

Given, Jock, Gerard Goggin, Michael Brealey, and Cathy Gray. Television: 2025: 20 Questions, 24 Viewpoints. Swinburne: Swinburne University of Technology, 2015.

Harris, Lauren Carroll. "When Will Netflix Start Investing in Australian Content?," Australian Centre for the Moving Image, October 7, 2015. acmi.net.au/acmi-channel/2016/ when-will-netflix-start-investing-in-australian-content/.

Idato, Michael. "Clinging to the Remnants of Youth." Sydney Morning Herald, September 17, 2012. http://www.smh.com.au/entertainment/tv-and-radio/clinging-to-the-remnants-of-youth-20120913-25vmk.html.

Lotz, Amanda. Portals: A Treatise on Internet Distributed Television. Ann Arbor, MI: Maize, 2017.

Meade, Amanda. "Australia's TV Channels Plunge into the Battle for the Water-Cooler." The Guardian Australia, February 12, 2017. www.theguardian.com/tv-and-radio/2017/ feb/12/australias-tv-channels-plunge-in-to-the-battle-for-the-water-cooler.

Roy Morgan Research. "More Australians Now Have SVOD than Foxtel." Article No. 6957, September 8, 2016. www.roymorgan.com/findings/6957-svod-overtakes-foxtelpay-tv-in-australia-august-2016-201609081005.

Roy Morgan Research. "Netflix Hits New High in Australia-7.6 Million." September 28, 2017. www.roymorgan.com/findings/7343-netflix-subscriptions-june-2017-201709270713.

Ryan, Peter. "Ten Network Casts 'Significant Doubt' Over Its Viability." The World Today, ABC News, April 27, 2017, http://www.abc.net.au/news/2017-04-27/ten-networkstruggles-to-survive-after-another-big-loss /8475774. 
Thomsen, Simon. "Netflix Just Cracked 10\% of the Australian Market." Business Insider Australia, October 15, 2015. http://www.businessinsider.co.au/netflix-just-cracked10--of-the-australian-market-2015-10.

Turner, Adam. "Is Netflix Hurting Aussie Broadcasters? Depends Who You Ask." The Age, March 11, 2016. http://theage.com.au/technology/gadgets-on-the-go/isnetflix-hurting-aussie-broadcasters-depends-who-you-ask-2016031-gngcvq.html (accessed June 30, 2016).

Turner, Graeme. "Television: Commercialization, the Decline of 'Nationing', and the Status of the Media Field." In Making Culture: Commercialisation, Transnationalism, and the State of 'Nationing' in Contemporary Australia, edited by David Rowe, Graeme Turner, and Emma Waterton, 64-74. London: Routledge, 2018. 